\title{
FORMAÇÃO DO ETHOS DA ESPOSA DO LÍDER POLÍTICO
}

\author{
(Formation of the ethos of the political \\ leader's wife)
}

Ida Lucia Machado

(Universidade Federal de Minas Gerais - UFMG-FALE)

\section{RÉSUMÉ}

On lance ici un regard sur une des "éminences grises " qui font partie de la vie d'un chef d'Etat, soit l'épouse ou la compagne de celui-ci. On veut montrer comment à nos jours, les médias s'approprient de ce personnage et aident à construire son éthos préalable qui peut échapper, se conformer ou s'opposer à son éthos discursif. Ces femmes médiatisées ou mises en valeur par les médias, ne sont-elles pás victimes d'une stratégie conçue pour rassurer ou "distraire » le peuple et mieux faire passer les actions de leurs époux?

Mots-clés: ethos préalable; ethos discursif; stratégies argumentatives.

\section{RESUMO}

Queremos aqui lançar um olhar sobre uma das muitas "eminências pardas" que rodeiam um chefe de Estado, no caso, sua esposa ou companheira. Gostaríamos de mostrar como as mídias se apropriam de tal personagem e ajudam a construir seu ethos prévio que pode escapar, ser igual ou se contrapor ao seu ethos discursivo. Será que essas mulheres, tão valorizadas pelas mídias, não seriam (em certos casos) apenas uma estratégia a mais utilizada para tranqüilizar ou distrair o povo fazendo-o "engolir" certas ações levadas a cabo por seus esposos?

Palavras-chaves: ethos prévio; ethos discursivo; estratégias argumentativas. 


\section{Introdução}

Abordaremos aqui a construção do ethos de uma figura feminina que volta, com bastante força, à mídia atual, pelo menos nos paises onde existe uma democracia: estamos aqui nos referindo à esposa do líder político ou à "primeira dama”.

Após fornecer nossa concepção de ethos, que, diga-se de passagem, é a mesma de Ruth Amossy iremos examinar o "ethos prévio" que envolve a mulher-esposa-do-chefe, de modo geral, citando uma figura histórica. Tentaremos mostrar que nela houve uma especial "transgressão de gênero" no que se refere ao "ethos prévio", uma vez confrontado com o "ethos discursivo" propriamente dito. De certo modo, este será o ponto de partida para que possamos verificar o éthé de outras mulheres ligadas à nossa história atual, através da observação de alguns enunciados midiáticos envolvendo as figuras de Marisa da Silva e Carla Bruni-Sarkozi, respectivamente esposas de Lula, nosso Presidente e de Nicolas Sarkozy, atual Presidente da França. Examinaremos a argumentação, ou melhor, dizendo, as dimensões argumentativas que nos levam a crer que o ethos (visto como um todo) que envolve as figuras femininas supracitadas (e tantas outras, suas "colegas") é construído para fins persuasivos, cuja visada seria, a priori, uma visada não-feminista. A hipótese que queremos aqui levantar é a de que histórias de vida podem ser habilmente tecidas em torno de personagens femininas com o objetivo de colocálas como "auxiliares" na edificação de éthé masculinos fortes. Mas, a questão que perdura e para a qual talvez não encontremos resposta é a seguinte: quando se nota, por parte de algumas companheiras ou esposas de líderes, uma "rebelião" contra a etiqueta de "primeira dama" vista como "emprego" ou "meio de se ganhar a vida" isso não seria também uma outra estratégia argumentativa forjada (como sempre) em favor de uma causa masculina? Pelo menos nos tempos atuais?

Nosso artigo é organizado em torno de casos específicos de mulheres que chamaríamos de "eminências pardas" de líderes 
políticos. No entanto, graças à benéfica explosão de diversas metodologias de AD no Brasil, acreditamos agora que devemos evitar um certo dogmatismo e que algumas expressões que parecem estar "coladas" a certos seres sociais devem ser examinadas caso a caso...

\section{Ethos prévio: considerações gerais}

Sabe-se que a noção de ethos, em geral, vem dos Clássicos e, mais precisamente, de Aristóteles. A partir daí este conceito tem sido examinado de forma diferenciada por uns e por outros, através dos tempos e, mais ainda, depois que ele fez sua entrada triunfal no campo da análise do discurso, em 1999, através de Amossy, Maingueneau e Haddad, organizadores do livro Images de soi dans le discours.

Após trabalhar amplamente a questão, Ruth Amossy a amplifica e lhe empresta mais cores em um livro posterior ao acima citado. Nele encontramos uma excelente definição para o fenômeno em pauta, definição esta simples e precisa:

Chamaremos ethos ou imagem prévia, em oposição ao simples ethos, /.../ a imagem que o auditório pode fazer do locutor antes mesmo que este tome a palavra. (AMOSSY, 2006, p.79) (Tradução nossa).

Como é fácil de se perceber, o ethos que antecede ao próprio discurso, ou seja, à própria pessoa antes que ela comece a discursar é construído graças a certos fatores que podem ser -para a pessoa em questão - positivos ou negativos. No caso da mulher do homem político, é melhor (para todos) que sejam positivos, aliás. Mas, o que seria "positivo" nesse caso? Que o homem político tenha uma esposa com um emprego, vida própria, que nem queira viver na residência oficial do governo, que continue seu trabalho (como o fez, por exemplo, a esposa de André Maurois, o primeiro dos Primeiros Ministros do governo François Mitterrand na França, em 1982) ou que seja uma esposa como "manda o figurino", mas, o "figurino" dos anos 50: uma mulher nem muito jovem nem muito idosa, 
sorridente, discreta, simples; a guardiã do lar do líder, mãe de seus filhos, aquela que tome para si todas as preocupações domésticas para que o "grande homem" governe em paz. Qual dessas duas imagens seria a mais positiva para o chefe de Estado e para o povo que ele governa?

Arriscando um pouco, diríamos que a última imagem feminina citada, ou seja, aquela que chamamos "de mulher dos anos 50" é ainda a grande preferida ou pelo menos a que tem sido mais difundida pela mídia nos últimos 40 anos. É uma imagem bastante estereotipada, pois, reduz a mulher a uma espécie de ser "apagado", que vive na "sombra" do marido ou companheiro, mas é, como dizem os franceses, é sem dúvida, une valeur sûre...

Devemos convir que a imagem do casal que nos governa envolvida por uma nuvem de amor e paz nos levará, ainda que adultos, a um universo infantil onde nossos pais eram fortes e belos e nos davam a devida segurança de que necessitávamos para encarar a vida: essa imagem, apesar de todos os estereótipos que carrega é ainda bastante forte, no sentido psicanalítico da palavra. Tais como os antigos súditos de um rei, os cidadãos de hoje teriam também a tendência de confundirem (em um inconsciente coletivo) seus governantes com seus pais. "Pai do povo": eis uma expressão que, de tão usada, passou da ordem do psicanalítico para a ordem do estereótipo ou mesmo do slogan. E atrás do pai, vem a mãe...

Citemos um exemplo recente, do ponto de vista histórico: o de Jacqueline Beaulieu e seu charmoso marido John Kennedy. Para o mundo, este casal era perfeito, ao lado de seus lindos filhos, em sua bem decorada casa: a imagem harmoniosa de uma família impecável. Além disso, Jacqueline, talvez por sua ascendência francesa que lhe conferia um charme e uma elegância mais européia que americana, encantava todas as mulheres do mundo e todos os chefes de Estado com quem se encontrava. Além disso, formavam um casal exemplar, que vivia de amor e de política, sendo que essas duas paixões se mostravam perfeitamente bem administradas e divididas entre o homem - o "provedor", aquele que saía para o trabalho - e a mulher - a guardiã irreprochável 
desse casamento dourado. Pelo menos foi esta a imagem que o casal transmitiu ao mundo. Imagem que começou a mostrar suas falhas ao público pouco a pouco, porém. Assim, no ano em que a atriz Marilyn Monroe cantou para toda a América e para o mundo "Feliz aniversário" para o Presidente americano, a história de sua ligação com John (ou com seu irmão) surgiu à tona. E, mais tarde, o espanto que se seguiu a isso quando todos viram a bela viúva do belo John, Jacqueline Kennedy tornar-se a esposa do não tão belo, mas, riquíssimo armador grego Onassis. A imprensa, diga-se de passagem, em comparação com a de hoje, foi até mais discreta e deixou escapar os fatos pouco a pouco. Jacqueline, como toda mulher enganada vingou-se do primeiro marido e, de certo modo, do mundo dourado que a política e o poderoso clã dos "Kennedys" haviam para ela construído. Seu primeiro ethos de esposa perfeita do líder americano foi literalmente jogado por terra, como uma máscara, com seu segundo casamento. Ela poderia ter passado para a posteridade como um ser fútil e interesseiro, uma "mulher" como tantas outras. Mas, o mito de "esposa perfeita" havia se colado muito bem à sua pele, à sua imagem. Anos depois da morte de Onassis e depois da morte da própria Jacqueline, o que volta agora à tona, com renovado sucesso é seu primeiro ethos...

Essa história de um "quase" conto de fadas político nos mostra que certos ethos ou certas construções mitológicas são dificilmente abandonados, após terem caído no gosto do povo. Ou dizendo de modo mais discursivo: no espaço coletivo do social.

O espaço social conta, pois, e muito, para a construção e manutenção de um ethos. No caso que nos interessa, tal espaço é construído por um hábil jogo de "vai-e-vem" realizado entre o pseudo-espaço íntimo do casal político e seu verdadeiro "espaço", que a priori desconhecemos ou que, pelo menos, levamos um certo tempo a conhecer ou pelo menos perceber. O pseudo-espaço íntimo é aquele que é desvelado para o mundo através da mídia, a portas abertas. É claro que esse espaço "invadido" sofre a pressão de um espaço coletivo, ou seja, de um espaço aberto à entrada de vários tipos de estereótipos que podem envolver a imagem de um casal 
presidencial. Em outros termos, deve haver uma adequação entre o casal visto em seu espaço íntimo e o casal enquanto espaço coletivo (geralmente liderado pelo homem ${ }^{1}$ ).

Como é fácil de se notar, esse casal "desdobrado" desempenha dois papéis distintos, sendo que o papel de casal amoroso (o do pseudo-espaço íntimo) assemelha-se bastante ao jogo cênico de um casal de atores em um palco de teatro.

Avançamos a hipótese de que o ethos prévio de uma mulher cujo marido alcança o mais alto poder encontra seu estereótipo em antigos contos de fadas: "Cinderela", "Pele de Asno", "Branca de Neve”, entre outros. São muitas as figuras femininas de tais contos sendo que várias aparecem nestes como personagens abandonadas, humilhadas, pobres, sem nobreza ou cuja nobreza foi usurpada...Em resumo: figuras femininas que estavam "adormecidas" de um certo modo e assim eram "ignoradas" dos olhos (curiosos) do mundo, e que "revivem" e ganham um lugar de destaque em uma nova vida, graças ao amor ou graças à ascensão do ser amado, verdadeiro protótipo do Príncipe Encantado de tais histórias.

O homem vem assim resgatar da "sombra" sua futura esposa, trazendo-a para a "luz" mas, atenção: para a "sua luz”. Se a heroína passa ou volta a brilhar isso se deve ao brilho do herói. Por incrível que pareça, o exemplo dos contos de nossa infância continua bem vivo: uma grande parte dos cidadãos e das cidadãs sonha com um "final feliz" e se este não acontece em suas próprias vidas, que ele seja mostrado, ao menos, na vida de um casal que é objeto de atenções por parte da mídia.

Tal casal ocupa assim, um lugar comum, ou um ethos prévio que diferentes nações gostam de observar ou de "consumir". Uma variação moderna desse ethos seria a do governante solteiro ou divorciado: ele continua a ser o Príncipe Encantado, mas, aquele que busca ainda a sua Princesa. E quanto mais "princesas" buscar, mais será admirado por uma certa visão machista que, infelizmente, ainda

1. Pois, é claro, existem exceções, ou seja casos em que é a mulher quem toma as rédeas do casal e no espaço político. 
domina em nossa sociedade. Exceções existem, é claro. Citemos uma: a do Prefeito de Paris, Bertrand Delanoë: homossexual assumido, ele é respeitado enquanto Maire de Paris e político, membro do Parti Socialiste francês.

Mas, este seria um assunto para uma outra ocasião. Fazendo uma viagem ao tempo, passemos agora, sem mais tardar, para o interessante caso da mulher de Péricles, o grande democrata grego.

\section{Aspásia - um "ethos prévio" que se chocou com um "ethos discursivo"}

Gostaríamos de citar aqui o curioso caso de Aspásia, a companheira de Péricles. Como nos lembra a historiadora Nicole Loraux, trata-se "sem dúvida, da mais célebre de todas as mulheres gregas da época clássica, porque ela foi a companheira de Péricles, que a amava e a respeitava” (2003, p.135).

É interessante notar que Aspásia nasceu em Mileto e foi considerada pelos gregos como estrangeira, durante toda sua vida. Talvez seja isso que a salvou de cair no lugar comum de "esposa" legítima do líder... Pois, Aspásia foi a companheira do chefe, sua amante ou concubina. E, no entanto, mesmo sendo mulher, em uma sociedade em que estas eram consideradas como seres inferiores, Aspásia sempre teve algo a dizer e foi ouvida. Além de bela e sedutora, ela era inteligente, muito inteligente. $\mathrm{E}$ seu homem a respeitava e escutava, a um ponto tal que esta admiração torna-se motivo de zombaria em peças teatrais cômicas da época.

O curioso é que a "voz oficial" (Apud Loraux, p.136) de Péricles, divulgada na obra de Tucídides, A guerra do Peloponeso, exortava a virtude das mulheres, seres "inferiores por natureza". A declaração feita por Péricles, amante apaixonado de Aspásia não deixa de ser paradoxal. Suas palavras foram "relidas", ou melhor, explicadas, não sem ironia, por Virgínia Woolf que disse o seguinte: “[...] a maior glória para uma mulher é que nunca se fale dela dizia 
Péricles, que foi justamente um dos homens sobre os quais mais se falou [na história]”. (Ib, tradução nossa).

Há, pois um "choque" entre o "dito" e o vivido de Péricles em face de Aspásia. Transpondo este caso para a análise do discurso, mais precisamente, para a análise argumentativa do discurso, diríamos então que ela, como toda mulher da época tinha seu "ethos prévio" e que este, na Grécia antiga, não poderia ser brilhante, pois era um ethos feminino. No entanto o "ethos discursivo" de Aspásia se choca com seu "ethos prévio". Como dissemos, ela era inteligente, muito inteligente e foi "mestra" de Sócrates... É o que diz, pelo menos Plutarco quando a menciona: "[...] sábia e versada na coisa política ela frequentava Sócrates e vários atenienses apreciavam sua inteligência” (Ib, p. 138, tradução nossa). Eis uma mulher excepcional citada por seus dotes intelectuais: mestra de retórica, tanto de Sócrates quanto de Péricles e aquele que o afirma é detentor de argumentos de autoridade (Plutarco). Note-se ainda que a palavra "mestra” que só existia em sua forma masculina em grego foi feminizada ao ser a ela aplicada.

Em 1939, o escritor brasileiro Monteiro Lobato escreveu o livro O minotauro no qual nos traz essa bela visão ou em outras palavras faz entrever o ethos (em sua totalidade) da mulher de Péricles, quando as personagens do Sítio do Pica-pau amarelo, fazendo uma viagem no tempo e no espaço chegam em Atenas. A inteligente avó das crianças personagens do livro, Dona Benta, trata Aspásia de "Dona Aspásia”, encanta-se com ela e com as pessoas que a rodeiam: Péricles é claro, mas também Heródoto e Sócrates. Admiração compartilhada pelo narrador do "Minotauro" que diz: "Poucas mulheres antigas revelaram a inteligência, a largueza de vistas e a compreensão da segunda esposa de Péricles" (1977, 13ª edição, p.99).

Como dissemos no começo desse segmento, talvez a sorte de Aspásia tenha sido a de nunca ter podido oficializar seu casamento com Péricles. Isso permitiu que ela, na qualidade de amante, fosse mais ouvida e respeitada... Aspásia não foi, pois, definitivamente, alguém que o líder político retirou da sombra para a claridade: Aspásia tinha sua luz própria e logo, escapou ao estereótipo que foi colado em tantas outras mulheres de chefes. Ou seria ela um estereótipo que foi 
invertido e convertido ao grau de "eminência parda", na vox populi, com o passar do tempo? Não tendo resposta para essa questão, gostaríamos de examinar agora, ainda que rapidamente, mais duas figuras femininas, bem próximas de nós: a de Marisa da Silva e o de Carla-Bruni Sarkozy.

\section{Dois éthé, duas personalidades diferentes: qual é a verdadeira, qual é a "mascarada"?}

Comecemos por Marisa da Silva, esposa de Luiz Inácio Lula da Silva. Marisa, como nós brasileiros a chamamos, tem sua história de vida, que é acoplada à história de vida de Lula. Marisa é sempre apresentada como alguém que ajudou o Presidente, com amor e discrição. Seu trabalho é em função dele. Vejamos, somente a título de ilustração, um trecho do retrato de Marisa feito pela jornalista Florência Costa, que encontramos na rubrica Perfil, da revista Isto é (online):

\section{Mulher de fibra}

Ao lado de Lula há 28 anos, Marisa também foi à luta em 80 e hoje é o esteio emocional da família.

Florência Costa

O presidente eleito, Luiz Inácio Lula da Silva, repetiu como um mantra nesta campanha que nunca esteve tão bem na sua vida. Boa parte desse alto-astral ele deve à mulher, Marisa Letícia da Silva. Aos 52 anos, esta neta de italianos é o alicerce psicológico e emocional de Lula. [...] Desta vez, com os quatro filhos já crescidos (o caçula, Luiz Cláudio, tem 17 anos), avó de dois meninos, Marisa acabou mergulhando de corpo e alma na campanha, à sua maneira. Ficou ao lado de Lula durante todo o tempo. Embora se apresentasse de modo discreto, sempre evitando entrevistas, a futura primeira-dama é uma mulher de temperamento muito forte. Marisa se transforma numa verdadeira leoa, se for preciso, para resguardar a privacidade de sua família ${ }^{2}$.

2. Grifos nossos. 
Nas frases sublinhadas, podemos notar que o ethos de Marisa é bem ligado ao que chamamos, no início desta fala, "ethos de primeira dama dos anos 50", ou seja, a descrição que é dada pelo sujeito-enunciador e que nos é endereçada, a nós, tu(s)-destinatários (conforme terminologia de Charaudeau, 1983), é a da mulher-mãe de família, atuante, mas, discreta, vivendo na sombra de seu maridochefe. Vemos que o sujeito-enunciador se esforça para tornar Marisa simpática aos olhos do leitor, mais que simpática, "maternal". Lembremo-nos de que ela é a esposa do atual "Pai do Povo". A construção aqui apresentada de sua imagem obedece a todos os estereótipos possíveis aplicáveis a uma "primeira dama” que, suave, mas bravamente, vela pela tranquilidade daquele que dirige a nação: é um ethos, digamos, que se encaixa como em uma fôrma, ao do Presidente. O “emprego", a "vocação" de Marisa é ser "primeira dama”. E todos ficam felizes com isso. Essa pelo menos é a mensagem que envolve o texto, ou como diria Charaudeau (2004) esse é o "tiers", ou o "elemento de base" desse tipo de discurso.

Em contrapartida, a imagem que a imprensa vem fornecendo da "primeira dama" da França é outra. Carla Bruni-Sarkozy já era Carla Bruni cantora e manequim antes de se tornar esposa do líder francês. Extremamente bela e elegante, ela já trazia um "ethos prévio" não muito recomendável para ser a mulher de um político da direita. Já como cantora - confessemos, simpática, com seu fio de voz - ela tinha um passado "carregado", com vários amantes, um filho de seis anos, fruto de uma ligação com o marido de Justine Lévy, filha de Bernard Henri-Lévy. Aliás, Justine, a esposa traída, não poupou Carla ao escrever um livro no qual relata como esta lhe roubou, literalmente, o amor do marido.

O casamento um tanto quanto rápido de Carla com Sarkozy, após o abandono que ele sofreu, por parte de sua bem amada esposa Cecília, sua semelhança com a mesma Cecília (só que mais jovem que esta), não passaram despercebidas da imprensa people, da qual Sarkozy e suas segunda e terceira esposas fazem parte. Este tipo de imprensa cresceu muito na França, mais que no Brasil. Os homens e mulheres políticos passaram a fazer parte desse "mundo de faz-de-conta" destilado por este 
tipo de imprensa já durante a campanha que opôs Sarkozy a Ségolène Royal e isso a um ponto tal, que a um dado momento, uma série de leitores franceses escreveram para diversas revistas pedindo que não se falasse mais dos amores de Sarkozy e Carla Bruni!

Mas a tentação é muito forte e a "primeira dama" tenta se afirmar (e parece estar conseguindo) no coração dos franceses. Sua elegância e sua facilidade de comunicação são comparadas com a de Jacqueline Kennedy; suas "pequenas frases" parecem mostrar que ela tem uma personalidade "própria", independente da de seu marido. Isso é uma novidade no mundo francês e tem funcionado de modo positivo para o referido marido, é claro.

Examinemos, rapidamente, alguns dos ditos de Carla Bruni que encontramos em publicações online francesas:

(1) “J'aurais tendance à m'imaginer davantage en Jackie Kennedy qu'en par exemple Mme de Gaulle, qui ressemble beaucoup plus à la femme française classique derrière son époux" a déclaré Carla BruniSarkozy dans une interview à Vanity Fair. Sorti au mois de juillet, le magazine américain n’a pas hésité à sous-titrer son article : "Liberté! Egalité! Nudité!” (C) Vanity Fair

(2) Je n'ai aucune intention de changer de métier. J'ai une fonction, mais ce n'est pas un métier. Une fonction comme la mienne, ce n'est pas un métier, j'en hérite avec mon mariage”. Interview pour le livre "Carla et Nicolas, la véritable histoire" - Paru en juin 2008 (Editions du Moment), Yves Azéroual et Valérie Benaïm. () Reuters

(3) "Mes réflexes épidermiques sont de gauche. Ce n'est pas une idéologie ni un système. Je ne suis pas une militante, je ne l'ai jamais été. J'ai l'impression que les gens qui sont complètement d'un côté ou de l'autre ne pensent qu'avec une partie du cerveau”. Interview dans Libération du 21 juin 2008. (C) Reuters

(4) "Les Français sont toujours négatifs. Ils adorent leur langue, donc chaque fois que quelque chose n'est pas en français, ils deviennent fous”. Interview du Dailymail, le 19 janvier 2008. (C) Reuters

(5) Signataire de la pétition lancée contre le recours aux tests ADN soumis par le gouvernement afin de lutter contre l'immigration clan- 
destine, Carla Bruni avait rétorqué: "Mon indignation a été immédiate”. (...) "Je déteste le 'tri' qu'implique l'immigration choisie (...). Qu'est-ce qu'il me serait arrivé si on avait imposé à mes parents des tests ADN ?”. Interview dans le magazine Elle, en 2007. (C) Reuters

(6)"J'aime être italienne. J'aime le tempérament italien et j'aime la cuisine italienne. Les Français sont souvent de mauvaise humeur, et les Italiens souvent de bonne humeur”. Interview du Dailymail, le 19 janvier 2008. (C) Reuters

(7) "Mes parents ont eux aussi toujours voté à gauche. C'est une tradition. Je ne voterai jamais à droite". Interview dans The Sunday Herald, en mai 2007. (C) Reuters

Carla Bruni diz em (2) que "ela tem uma função, mas que isso não é um emprego”, depois de ter dito, em (1) que se pudesse escolher uma imagem (um ethos) ela escolheria Jacqueline Kennedy e não Yvonne De Gaulle (que era uma verdadeira sombra de seu marido, no sentido literal da palavra). Nessa época ${ }^{3}$ vemos que Carla Bruni não hesita em assumir sua italianidade em (4), (5) e (6). Curiosamente, ela afirma ser "da esquerda" por "tradição familiar" (7) e diz ter detestado uma das medidas do governo de seu marido (5).

Mais ou menos na época dessas declarações, Carla fez apelo à sua antiga paixão (a canção) e gravou discos, mostrando assim que tentava manter uma carreira à parte da de seu marido.

O que dizer desse ethos que tenta se manter "marginal" em face de um político reacionário como Sarkozy? Trata-se de um golpe publicitário? Se for isso, temos que reconhecer que essa estratégia não deixa de ser interessante: "Meu marido é Presidente, mas, eu tenho a minha vida, os meus amigos, eu sou cantora e continuo a ser cantora, etc. e tal" diria Carla, para resumir. Carla-marginal compõe assim um casal com Sarkozy-reacionário. Bela, inteligente, sabendo "manter o ritmo sem perder a ginga”, como afirma a imprensa brasileira, através da

3. Os ditos da primeira dama francesa mudaram, segundo o jornal Le Nouvel Observateur (mês de fevereiro/2009) pois ela teria afirmado não se sentir mais italiana e sim francesa. 
revista Marie-Claire (dezembro 2008), Carla nos parece ser, entretanto, mais um joguete nas mãos do ambicioso chefe de Estado francês. Um belo instrumento de diversão que pode distrair os franceses de sua bizarra forma de governar. Só o tempo dirá se temos ou não razão em afirmar isso.

Chegamos aqui a um impasse. Se alguns franceses e alguns estrangeiros são cativados por Carla é porque, justiça seja feita, ela os "distrai”, de algum modo, com sua elegância, sua beleza e mesmo sua voz e seu passado de manequim. Já Marisa, no seu lugar de esposa dedicada e mãe e avó digna de respeito, não é passível de "distrair" os brasileiros...

De todo modo, nenhum dos dois casos mostra um ethos feminino ideal. Há muito terreno ainda a ser conquistado pelas mulheres, ou seja: elas precisam cuidar muito bem de seus éthé, e se os "prévios” já vem "contaminados" pelo fato de "ser mulher" e querer fazer política, elas podem sempre se salvar pelos seus éthé discursivos. Em resumo: prosseguir, modernamente, com as adaptações que nossa época permite, o que Aspásia já havia começado, em sua longínqua Atenas, na quase metade do V século antes de Cristo (440 a 429).

Recebido em: setembro de 2009 Aprovado em: outubro de 2009 idalumachado@terra.com.br

\section{Referências Bibliográficas}

AMOSSY, R. (sous la direction) Images de soi dans le discours - la construction de l'ethos, Lausanne et Paris: Délachaux et Niestlé, 1999. AMOSSY, R. L'argumentation dans le discours. Paris: Armand Colin, 2006, 2a édition.

CHARAUDEAU, P. Langage et Discours. Paris: Hachette, 1983. 
CHARAUDEAU, P. Tiers, où es-tu ? A propos du tiers dans le discours, in: CHARAUDEAU, P. et MONTES, R. La voix cachée du tiers. Paris : L'Harmattan, 2004, p. 19-41.

HOWATSON, M.C. (sous la direction), Dictionnaire de l'Antiquité, Paris: Robert Laffont, Bouquins, 1993.

LORAUX, N., Aspasie, l'Etrangère, l'intellectuelle, in: LORAUX, N. (sous la direction) La Grèce au féminin, Paris : Les Belles Lettres, 2003, p.133-166.

MONTEIRO LOBATO, J.B.R. O Minotauro. São Paulo: Editora Brasiliense, 1977, $13^{\mathrm{a}}$ edição.

Publicações online francesas: France-Inter du 21 juin 2008; msn.hotmail.fr Politique- les petites phrases de Carla Bruni, 2008.

Publicação online brasileira: Istoé - Perfil, 2008.

Revista Marie-Claire, versão brasileira, dezembro 2008. 